\title{
A study of the utility of novel non-invasive urinary and serum biomarkers of blunt kidney injury in a rat model: NGAL, KIM-1, and IL-18
}

\author{
ÜNAL BAKAL ${ }^{l}$, MEHMET SARAC ${ }^{l}$, TUGAY TARTAR ${ }^{l}$, DILARA KAMAN², AHMET KAZEZ ${ }^{1}$ \\ ${ }^{1}$ Department of Pediatric Surgery, Faculty of Medicine, Firat University, Elazlğ, Turkey \\ ${ }^{2}$ Department of Medical Biochemistry and Clinical Biochemistry, Faculty of Medicine, Firat University, Elazı̆g, Turkey
}

\begin{abstract}
This study investigated changes in the concentrations of serum and urine neutrophil gelatinase lipocalin (NGAL), kidney injury molecule 1 (KIM-1), interleukin $18(I L-18)$, and cystatin-C (Cys-C) induced by parenchymal and tubular damage following blunt kidney trauma, as well as their potential utility as biomarkers in the detection and follow-up of patients with suspected blunt renal trauma. Three-month-old male Sprague-Dawley rats $(n=18)$ were divided into three groups $(n=6$ in each): group 1: control group (no intervention); group 2: sham group (explorative surgery and exposure of the left kidneys); and group 3: trauma group (explorative surgery and induction of blunt renal trauma of the left kidneys). Serum and urine samples were collected before and 12-24, 36-48, and 60-72 hours later for NGAL, KIM-1, IL-18, and Cys-C measurements. In the trauma group, there was a statistically significant increase in post-operative NGAL, KIM-1, and IL-18 values after 12-24 h and 36-48 h, as compared with pre-operative values. There was also a statistically significant increase in post-operative serum and urine Cys-C values after 60-72 h, as compared with pre-operative values. NGAL, KIM-1, and IL-18 may represent novel non-invasive descriptive candidate biomarkers of early-stage tubular damage in children with renal trauma.
\end{abstract}

Key words: biomarkers, blunt kidney injury, neutrophil gelatinase lipocalin, kidney injury molecule 1, interleukin 18, cystatin-C.

(Centr Eur J Immunol 2019; 44 (3): 219-225)

\section{Introduction}

Trauma is a major cause of paediatric mortality. Most intra-abdominal organ injuries are the result of blunt trauma, with the genitourinary system involved in nearly $10 \%$ of cases $[1,2]$. The kidneys are the most frequent site of genitourinary system organ injury. Despite severe renal trauma, haematuria is not seen in one-fourth of cases, and clinical manifestations can lead to a mild course [3-5]. With regard to non-invasive radiological delineation of renal trauma, ultrasound imaging is inadequate, especially in cases of low-grade trauma. A definitive diagnosis requires the use of contrast-enhanced computed tomography, which exposes children to high doses of radiation. Therefore, there is an ongoing search for non-invasive diagnostic methods or markers of renal trauma [6].

Recent studies have reported that neutrophil gelatinase lipocalin (NGAL), kidney injury molecule 1 (KIM-1), interleukin (IL)-18, and cystatin-C (Cys-C) could serve as descriptive biomarkers for various pathologies (e.g. ischaemia, nephrotoxicity, nephropathy, and acute renal failure) involved in end-stage renal damage. Serum and urinary concentrations of these markers are elevated in patients with renal damage, especially renal tubular damage, but not in those without kidney damage [7-11].

The aim of this experimental study was to investigate changes in the concentrations of serum and urine NGAL, KIM-1, IL-18, and Cys-C induced by parenchymal and tubular damage following blunt kidney trauma, as well as their potential as biomarkers in the detection and follow-up of patients with suspected blunt renal trauma.

\section{Material and methods}

This study was performed in the Centre of Experimental Investigations after obtaining approval from the Direc-

Correspondence: Ünal Bakal, MD, Department of Pediatric Surgery, Faculty of Medicine, Firat University, 23100 Elazığ, Turkey, e-mail: unalbakal@ hotmail.com

Submitted: 11.03.2017; Accepted: 8.05.2017 
torate of the Ethics Committee of Animal Experiments. Three-month-old male Sprague-Dawley rats $(n=18)$ weighing 280-330 g were included in the study. The rats were housed in cages under standard laboratory conditions (fixed temperature and humidity and a $12 \mathrm{~h}$ light $/ 12 \mathrm{~h}$ dark cycle). All the animals had access to fresh water, and they were fed a standard diet of pellets.

\section{Experimental groups and procedures}

The rats were divided into the following three groups: group 1: control group $(n=6)$; group 2: sham group $(n=6)$ (explorative surgery and exposure of the left kidneys); and group 3: trauma group $(n=6)$ (explorative surgery and induction of blunt renal trauma of the left kidneys). Control group: no intervention was performed. Sham group: under general anaesthesia, through a midline incision, the abdominal cavity was entered. The left kidneys of the rats were exposed, and the abdominal cavity was then closed. The rats were placed in metabolic cages containing standard pellets and tap water and monitored. Trauma group: the renal trauma model and apparatus were performed according to described by Hanbeyoglu et al. [12]. Under general anaesthesia, through a midline incision, the abdominal cavity was entered. The left kidney was dissected away from the perirenal fat tissue and elevated from its lateral edges. Taking care to protect the renal pedicle, renal injury was induced by the way targeted the kidney parenchyma in the spoon of the device. A $20 \mathrm{~g}$ cylindrical object was dropped once on the kidney from a height of $30 \mathrm{~cm}$ to induce grade I and III injuries (Fig. 1). The object was then removed, and the kidney was returned to its anatomical place. At the injured site, macroscopic haematomas and lacerations were observed. The grade of renal trauma was classified according to the organ injury scale [13]. The ab-

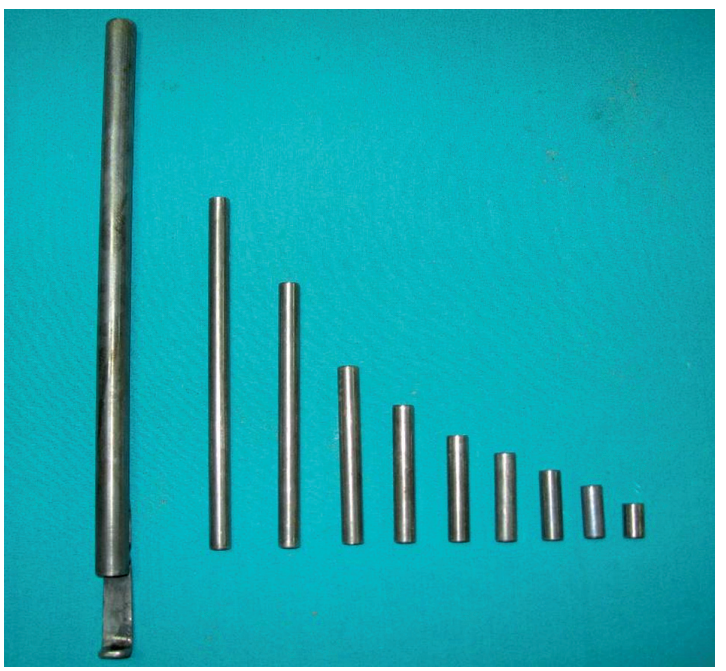

Fig. 1. The instruments used in blunt trauma of the kidney and application dominal cavity was closed as described above, and the rats were placed in metabolic cages.

All the experimental procedures were performed under aseptic conditions. General anaesthesia was instituted via the administration of intramuscular ketamine hydrochloride (Ketalar ${ }^{\circledR}$, Eczacibasi, Istanbul, Turkey) and xylazine hydrochloride (Rompun ${ }^{\circledR}$, Bayer, Istanbul, Turkey), with doses of $50 \mathrm{mg} / \mathrm{kg}$ and $4 \mathrm{mg} / \mathrm{kg}$, respectively.

In all three groups, the same post-procedural criteria of follow-up and care were applied. Serum and urine samples were collected before and 12-24 h, 36-48 h, and 60-72 h after the surgical procedures.

\section{Retrieval, collection, and evaluation of the serum and urine samples}

Prior to the experimental procedures, serum and urine samples were collected from all the animals for analysis of NGAL, KIM-1, IL-18, Cys-C, and creatinine. The serum samples were placed in tubes containing EDTA and centrifuged at $2500 \mathrm{rpm}$ for $20 \mathrm{~min}$. The serum samples were aliquoted and stored at $-20^{\circ} \mathrm{C}$ until the analysis. The urine samples were placed in sterile urine collection containers and centrifuged at $2500 \mathrm{rpm}$ for $20 \mathrm{~min}$. The samples were stored at $-20^{\circ} \mathrm{C}$ until they were used.

The sandwich ELISA method and commercial kits were used to measure NGAL (Sunred ${ }^{\circledR}$; catalogue no. 20111-0763), KIM-1 (Sunred ${ }^{\circledR}$; catalogue no. 201-11-0550), IL-18 (Sunred ${ }^{\circledR}$; catalogue no. 201-11-0118), and Cys-C (Sunred $^{\circledR}$; catalogue no. 201-11-0146). The serum samples and standard solutions were pipetted into wells coated with polyclonal antibodies specific to KIM-1, NGAL, Cys-C, and IL-18. A biotinised polyclonal anti-human antibody was added to the wells. Following incubation, unbound antibody was removed by washing. A streptavidin-peroxidase-enzyme conjugate was then added to the wells to ensure its conjugation with biotinised antibodies. Following a second incubation, unbound antibody-enzyme conjugate was removed by washing. A substrate was added to the wells. The intensity of the colour increased after the third incubation. Enzymatic activity was measured using a spectrophotometer at a wavelength of $450 \mathrm{~nm}$. The intensity of the colour was in direct proportion to the concentrations of KIM-1, NGAL, Cys-C, and IL-18 in the sample. The results were expressed in $\mathrm{pg} / \mathrm{ml}$ for KIM-1, $\mathrm{ng} / \mathrm{ml}$ for NGAL, $\mu \mathrm{g} / \mathrm{ml}$ for Cys-C, and $\mathrm{ng} / \mathrm{l}$ for IL-18. The tests were sensitive for KIM-1 at $23.776 \mathrm{pg} / \mathrm{ml}$ and for NGAL at 0.268 $\mathrm{ng} / \mathrm{ml}$. The intra-assay and inter-assay CVs for KIM-1 and NGAL were $<9 \%$ and $<11 \%$, respectively. The tests were sensitive for Cys-C at $0.05 \mu \mathrm{g} / \mathrm{ml}$ and for IL-18 at $0.472 \mathrm{ng} / \mathrm{l}$. The intra-assay and inter-assay CVs for these two parameters were $<8 \%$ and $<10 \%$, respectively.

Urine creatinine levels were measured using an autoanalyser (Siemens Advia 1800 Chemistry System, Siemens, Tokyo, Japan) and commercial kits (Siemens, 
Table 1. Mean NGAL and KIM-1 levels among the groups

\begin{tabular}{|c|c|c|c|c|c|}
\hline Groups & & Serum NGAL (ng/ml) & Urine NGAL (ng/ml) & Serum KIM-1 (pg/ml) & Urine KIM-1 (pg/ml) \\
\hline \multirow[t]{4}{*}{ Trauma } & Preoperative & $11.8818 \pm 0.994^{*}$ & $10.6370 \pm 3.560^{*}$ & $1688.104 \pm 182.919$ & $795.900 \pm 210.32^{\mathrm{b}}$ \\
\hline & $12-24 \mathrm{~h}$ & $15.4150 \pm 1.396$ & $19.0618 \pm 6.121$ & $1715.186 \pm 152.086$ & $1524.138 \pm 189.77$ \\
\hline & $36-48 \mathrm{~h}$ & $14.9203 \pm 1.501^{\mathrm{a}}$ & $17.5447 \pm 1.760^{\mathrm{a}}$ & $1820.699 \pm 418.497$ & $1335.825 \pm 87.94$ \\
\hline & $60-72 \mathrm{~h}$ & $8.7176 \pm 2.361$ & $9.6256 \pm 1.967$ & $3083.950 \pm 5373.588$ & $1578.804 \pm 171.56$ \\
\hline \multirow[t]{4}{*}{ Sham } & Preoperative & $12.6926 \pm 1.315$ & $15.7668 \pm 1.087$ & $1645.678 \pm 205.943$ & $1231.176 \pm 103949$ \\
\hline & $12-24 \mathrm{~h}$ & $15.4468 \pm 3.200$ & $10.8982 \pm 7.013$ & $1621.678 \pm 205.943$ & $1387.296 \pm 291.799$ \\
\hline & $36-48 \mathrm{~h}$ & $13.7232 \pm 1.839$ & $7.7578 \pm 3.534$ & $1657.600 \pm 371.222$ & $1289.059 \pm 457.640$ \\
\hline & $60-72 \mathrm{~h}$ & $7.8294 \pm 1.188$ & $8.2348 \pm 1.507$ & $1679.948 \pm 378.259$ & $1669.084 \pm 215.677$ \\
\hline \multirow[t]{4}{*}{ Control } & 0 & $15.7223 \pm 3.795$ & $14.5518 \pm 1.553$ & $1831.001 \pm 114.490$ & $1303.568 \pm 95.511$ \\
\hline & $12-24 \mathrm{~h}$ & $11.8910 \pm 1.360$ & $17.4468 \pm 3.540$ & $1659.729 \pm 319771$ & $1484.807 \pm 227.207$ \\
\hline & $36-48 \mathrm{~h}$ & $130525 \pm 0.677$ & $11.1660 \pm 1.243$ & $1598.380 \pm 226.060$ & $1288.442 \pm 107.672$ \\
\hline & $60-72 \mathrm{~h}$ & $7.8425 \pm 0.537$ & $11.7203 \pm 1.960$ & $1219.684 \pm 149.426$ & $1440.543 \pm 187.893$ \\
\hline
\end{tabular}

${ }^{*}$ Significant values were detected at preoperative and postoperative $12-24 \mathrm{~h}$ and $36-48 \mathrm{~h}(\mathrm{p}<0.05)$, ${ }^{a}$ significant values were detected at postoperative $36-48 \mathrm{~h}$ and $60-72 h(p<0.05),{ }^{b}$ significant values were detected at preoperative and postoperative 12-24 $h, 36-48 h$, and 60-72 $h(p<0.05)$
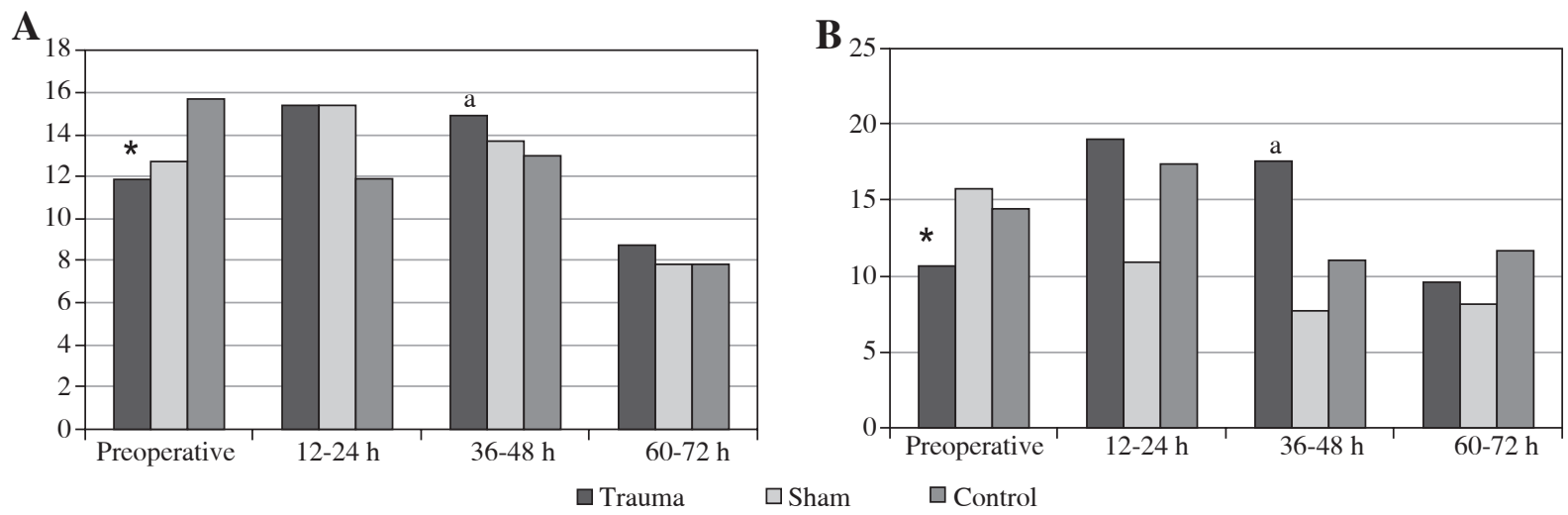

Fig. 2. Mean serum (A) and urine $(\mathbf{B})$ levels of $\operatorname{NGAL}(\mathrm{ng} / \mathrm{ml})$; * - significant values were detected preoperatively and at postoperative $12-24 \mathrm{~h}, 36-48 \mathrm{~h}$, and $60-72 \mathrm{~h}(p<0.05)$, a - significant values were detected at postoperative $36-48 \mathrm{~h}$ and $60-72 \mathrm{~h}(p<0.05)$

Camberley, UK) in the clinical chemistry laboratory of our university.

\section{Statistical analysis}

For descriptive statistics, parametric data were presented as mean \pm standard deviation (mean $\pm \mathrm{SD}$ ). For pairwise comparisons, the Mann-Whitney $U$ test was used. For inter- and intra-group comparisons, Kruskal-Wallis and Wilcoxon rank tests were used, respectively. A value of $p<0.05$ was considered as significant.

\section{Results}

No animals died during the study. Grade II and III renal injuries, including macroscopic haematomas, were observed in all the rats in the trauma group.
When the pre-operative values of the trauma and sham groups were compared with the baseline values of the control group, there were no statistically significant differences in any of the parametric data $(p>0.05)$. There was also no significant difference between the control and sham groups in successive serum NGAL measurements $(p>0.05)$. In the trauma group, post-operative NGAL values showed a statistically significant increase after $12-24 \mathrm{~h}$ and 36-48 h, compared with pre-operative values $(p<0.05)$. At the $48^{\text {th }}$ post-operative hour, serum NGAL levels decreased significantly $(p<0.05)$ and approached normal levels (Table 1) (Fig. 2A). There was no significant difference in successive urine NGAL measurements in the control and sham groups $(p>0.05)$. In contrast, in the trauma group, when compared with pre-operative values, post-operative urine NGAL values showed a statistically 
Table 2. Mean IL-18, cystatin-C, and creatinine levels among the groups

\begin{tabular}{|c|c|c|c|c|c|c|}
\hline Groups & & Serum IL-18 (ng/l) & Urine IL-18 (ng/l) & $\begin{array}{c}\text { Serum cystatin-C } \\
(\mu \mathrm{g} / \mathrm{ml})\end{array}$ & $\begin{array}{l}\text { Urine cystatin-C } \\
\qquad(\mu \mathrm{g} / \mathrm{ml})\end{array}$ & $\begin{array}{c}\text { Urine creatinine } \\
(\mathbf{m g} / \mathbf{d l})\end{array}$ \\
\hline \multirow[t]{4}{*}{ Trauma } & Preoperative & $37.161 \pm 4.485^{\mathrm{a}}$ & $25.244 \pm 5.305^{\mathrm{b}}$ & $3.743 \pm 0.672^{\mathrm{c}}$ & $2.096 \pm 0.652^{\mathrm{c}}$ & $18.996 \pm 7.553^{\mathrm{b}}$ \\
\hline & $12-24 \mathrm{~h}$ & $45.931 \pm 13.320$ & $40.764 \pm 10.124$ & $3.089 \pm 0.532$ & $1.939 \pm 0.741$ & $67.828 \pm 17.620$ \\
\hline & $36-48 \mathrm{~h}$ & $65.199 \pm 12.041$ & $49.360 \pm 35.830$ & $4.441 \pm 0.954$ & $1.593 \pm 0.307$ & $97600 \pm 38.788$ \\
\hline & $60-72 \mathrm{~h}$ & $76.570 \pm 10.173$ & $41.038 \pm 3.635$ & $4.726 \pm 1.331$ & $2.909 \pm 0.139$ & $13.305 \pm 4.320$ \\
\hline \multirow[t]{4}{*}{ Sham } & Preoperative & $32.363 \pm 13.853^{\mathrm{b}}$ & $35.330 \pm 3.285$ & $4.043 \pm 0.591$ & $3.364 \pm 0.279$ & $43.710 \pm 26.236^{*}$ \\
\hline & $12-24 \mathrm{~h}$ & $30.052 \pm 13.853$ & $32.793 \pm 8.495$ & $4.513 \pm 2.123$ & $1.543 \pm 0.614$ & $121.114 \pm 55.093$ \\
\hline & $36-48 \mathrm{~h}$ & $82.069 \pm 5.839$ & $32.058 \pm 6955$ & $3.435 \pm 0.410$ & $1.567 \pm 0.239$ & $125.026 \pm 47.683$ \\
\hline & $60-72 \mathrm{~h}$ & $92.113 \pm 29.110$ & $39.650 \pm 5.439$ & $3.595 \pm 1.152$ & $2.443 \pm 0.671$ & $20.304 \pm 7.279$ \\
\hline \multirow[t]{4}{*}{ Control } & 0 & $45.438 \pm 2.309$ & $30.488 \pm 3.567$ & $3.856 \pm 0.248$ & $3.083 \pm 0.303$ & $63912 \pm 22.681$ \\
\hline & $12-24 \mathrm{~h}$ & $52.453 \pm 17.066$ & $35.785 \pm 3.999$ & $5.752 \pm 1.353$ & $1.638 \pm 0.124$ & $137.495 \pm 1.986$ \\
\hline & $36-48 \mathrm{~h}$ & $80.890 \pm 6220$ & $30.592 \pm 2.100$ & $6.707 \pm 4.027$ & $1.561 \pm 0.272$ & $55.795 \pm 22.590$ \\
\hline & $60-72 \mathrm{~h}$ & $82.719 \pm 3.627$ & $40.520 \pm 4.144$ & $3.951 \pm 1.525$ & $1.830 \pm 0.168$ & $41.267 \pm 18.842$ \\
\hline
\end{tabular}

significant increase after $12-24 \mathrm{~h}$ and $36-48 \mathrm{~h}(p<0.05)$. At the $48^{\text {th }}$ post-operative hour, serum levels of NGAL decreased significantly $(p<0.05)$ and approached to the normal values (Table 1, Fig. 2B).

In the control and sham groups, no significant change was observed in successive urine KIM-1 measurements $(p>0.05)$, while there was a significant difference in the KIM-1 values after the trauma $(p>0.05)$. In contrast, in the trauma group, when compared with pre-operative values, the KIM-1 values were statistically significantly higher at post-operative $12-24 \mathrm{~h}, 36-48 \mathrm{~h}$, and $60-72 \mathrm{~h}$ $(p<0.05)$ (Table 1, Fig. 3A).

In the control group, no significant change was observed in serum IL-18 levels $(p>0.05)$. In contrast, in the sham and trauma groups, serum IL-18 levels measured at post-operative $36-48 \mathrm{~h}$ and $60-72 \mathrm{~h}$ showed a significant increase when compared with pre-operative levels $(p<0.05)$. There was no significant change in urine IL-18 levels in the control and sham groups $(p>0.05)$. However, in the trauma group, IL-18 levels showed a statistically significant increase at post-operative $12-24 \mathrm{~h}, 36-48 \mathrm{~h}$, and 60-72 h when compared with pre-operative values $(p<0.05)$, as shown in Table 2 and Figure 3B.

In the control and sham groups, there was no significant difference in serum and urine Cys-C levels $(p>0.05$ for both). However, in the trauma group, there was a statistically significant increase in both serum and urine Cys-C levels at post-operative 60-72 $\mathrm{h}$ when compared with pre-operative values $(p<0.05$ for both) (Table 2).

In both the sham and trauma groups, urine creatinine values increased after post-operative 12-24 h $(p<0.05)$ (Table 2).

\section{Discussion}

The present study investigated the potential utility of non-invasive serum and urine markers in the detection of blunt renal trauma. The results suggest that urine KIM-1 and IL-18 and urine and blood NGAL values have potential as non-invasive markers of blunt renal trauma.

In a wide spectrum of studies, researchers have evaluated the usefulness of measurements of serum and urine enzymes in the detection of kidney diseases [7-10, 12]. Serum and urine NGAL, KIM-1, IL-8, and Cys-C tests have been shown to be important in the detection of renal damage that develops secondary to ischaemia or other diseases and in monitoring these diseases [14-16]. For example, studies showed that they could be used to quantify and predict the severity of renal damage before the deterioration of renal function [17-20]. However, information is lacking in the literature on changes in serum and urine levels of KIM-1, NGAL, IL-18, and Cys-C enzymes in the presence of traumatic injury.

Traumatic injury is an important cause of mortality and morbidity in children. In the genitourinary system, the kidneys are the most frequently injured organs. In a patient with whole-body trauma, urinary analysis aimed at detecting the presence of haematuria, in addition to an ultrasonographic examination, is the easiest way to detect genitourinary system injury $[2,6]$. However, even in cases of severe renal injury, at the onset, macroscopic and microscopic haematuria are seen in only $65 \%$ and $32.7 \%$ of cases, respectively. Thus, ultrasound is inadequate in the determination of renal injuries. Instead, contrast-enhanced $\mathrm{CT}$, which exposes children to high doses of radiation, is 
A

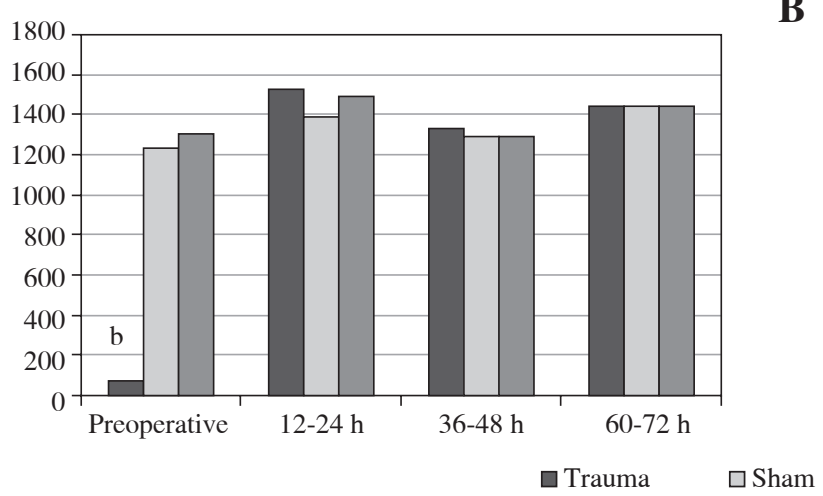

B

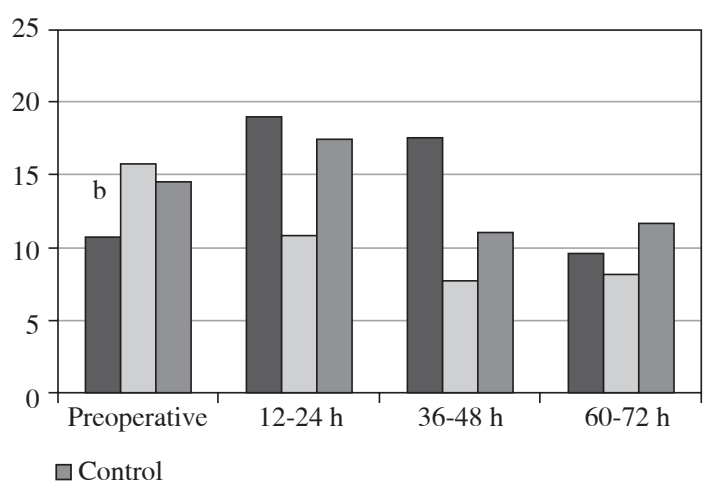

Fig. 3. A) Mean urine levels of KIM-1 (ng/ml), B) mean urine levels of IL-18 (ng/l); b - significant values were detected preoperatively and at postoperative $12-24 \mathrm{~h}, 36-48 \mathrm{~h}$, and $60-72 \mathrm{~h}(p<0.05)$

needed for the detection of renal trauma in paediatric cases $[2,6]$.

NGAL is a well-known member of the lipocalin family. Previous studies reported variations in levels of NGAL in the presence of renal damage. Immunohistochemical analyses revealed increases in the levels of NGAL in renal proximal tubules following ischemia lasting $3 \mathrm{~h}$ [21]. Subsequent studies demonstrated that urinary levels of NGAL were elevated after renal ischaemia-reperfusion injury and suggested that NGAL could be a potential diagnostic biomarker of the development of acute renal ischaemia in paediatric patients undergoing cardiac surgery [22]. The same studies indicated that the urinary level of NGAL could be useful in the assessment of contrast-induced nephropathy in children [23]. Thus, these studies pointed to the effectiveness of NGAL, both in aiding the diagnosis and in predicting the prognosis. In the present study, in the trauma group, the serum and urine levels of NGAL were statistically significantly increased immediately after the trauma, as compared to those of the sham and control groups. Thus, the present study confirmed that NGAL was an important non-invasive marker in the early recognition of blunt renal trauma.

Ichimura et al. [17] reported that KIM-1 was not present at a detectable level in normal rat kidneys, whereas it was increased in the kidneys of rats after acute renal ischaemia. Similarly, another study indicated that KIM-I might be preferable to conventional biomarkers in human studies [24]. In a study of acute renal ischaemia that developed following exposure to cisplatin, serum creatinine and BUN or urinary NAG were more valuable biomarkers than glycosuria and proteinuria [25]. Many previous studies of non-traumatic renal damage determined the sensitivity and specificity of KIM-1 in the detection of renal damage $[14,16,17]$. The present study also found significantly higher urinary levels of KIM-1 in trauma-induced rats, without any significant change in serum KIM-1 levels.
Levels of IL-18, a pro-inflammatory cytokine present in proximal tubules, increase in cases of acute kidney injury. Parikh et al. indicated that IL-18 levels were elevated in patients with acute renal ischaemia but not in patients with other renal diseases [26]. Another study reported elevated levels of IL-18 in cisplatin-induced acute renal ischaemia [11]. However, Haase et al. [27] suggested that IL-18 was not a suitable marker of acute renal ischaemia in patients undergoing cardiac surgery. In the present study, urine IL-18 levels of the trauma group were significantly higher than those of the sham and control groups. However, serum IL-18 levels were significantly higher in both the sham and trauma groups compared with the control group. Therefore, although urine IL-18 levels seem to increase secondarily to renal trauma, elevated serum levels of IL-18 do not seem to be associated with renal trauma.

Increased levels of Cys-C are found in the early phase of acute renal ischaemia, especially in intensive care unit patients [15, 28]. In a previous study, Nejat et al. [29] stated that Cys-C could serve as a diagnostic tool in the prediction of mortality. In the present study, in the trauma group, serum and urine Cys-C levels reached their highest level within 60-72 h. We speculate that the significantly higher Cys-C levels at postoperative $60-72 \mathrm{~h}$ originated from differences in the aetiology of renal tubular damage. These findings suggest that although Cys-C levels do not seem to be beneficial in the early detection of trauma, they could be useful in its follow-up.

Urine creatinine (serum creatinine and urea) and creatinine clearance are routinely used in laboratories for the evaluation of renal glomerular damage [30]. In the present study, urine creatinine levels showed a significant increase in both the trauma and sham groups. This increase was probably due to surgical stress rather than tubular damage.

In the evaluation of renal glomerular damage, various indicators, such as serum creatinine and urea and creatinine clearance, are routinely used. A number of 
biochemical parameters are available to evaluate tubular damage. These include urinary alkaline phosphatase, gamma glutamyl transferase, leucine aminopeptidase, alanine aminopeptidase, $\beta$-galactosidase, neutral endopeptidase, $\alpha$-glucosidase, and $\mathrm{N}$-acetyl- $\beta$-D glucosaminidase measurements. However, the poor stability of these molecules and difficulties in collecting urine for $24 \mathrm{~h}$ restrict the use of most of these indicators [12, 31-34]. NGAL, KIM-1, and IL- 8 have potential as biochemical parameters in the determination of renal damage.

\section{Conclusions}

Within the limitations of the present study, we conclude that NGAL, KIM-1, and IL-18 may be simple, effective and novel non-invasive descriptive candidate urinary and serum biomarkers of early tubular damage following renal trauma. However, detailed clinical and experimental studies are needed to determine the potential utility of these markers in routine care. Such studies could lead to major advances in the use of non-invasive biomarkers in renal trauma. The availability of such biomarkers would decrease the use of contrast materials for diagnostic purposes, thereby reducing radiation exposure and the need for invasive procedures.

\section{Acknowledgements}

This study was supported by the Scientific Research Projects Unit of Firat University (Project no. TF.14.50).

\section{The authors declare no conflict of interest.}

\section{References}

1. Stauffer UG (1995): Surgical and critical care management of children with life-threatening injuries: the Swiss experience. J Pediatr Surg 30: 903-910.

2. Wessel LM, Scholz S, Jester I, et al. (2000): Management of kidney injuries in children with blunt abdominal trauma. J Pediatr Surg 35: 1326-1330.

3. Cooper A, Barlow B, DiScala C, et al. (1994): Mortality and truncal injury: the pediatric perspective. J Pediatr Surg 29: 33-38.

4. Snyder CL, Jain VN, Saltzman DA, et al. (1990): Blunt trauma in adults and children: a comparative analysis. J Trauma 30: $1239-1245$.

5. Kivioja AH, Myllynen PJ, Rokkanen PU, et al. (1990): Is the treatment of the most severe multiply injured patients worth the effort? A follow-up examination 5 to 20 years after severe multiple injury. J Trauma 30: 480-483.

6. Eassa W, El-Ghar MA, Jednak R, et al. (2010): Nonoperative management of grade 5 renal injury in children: does it have a place? Eur Urol 57: 154-161.

7. Petrovic S, Bogavac-Stanojevic N, Peco-Antic A, et al. (2013): Clinical application neutrophil gelatinase-associated lipocalin and kidney injury molecule- 1 as indicators of in- flammation persistence and acute kidney injury in children with urinary tract infection. Biomed Res Int 2013: 947157.

8. Dent CL, Ma Q, Dastrala S, et al. (2007): Plasma neutrophil gelatinase-associated lipocalin predicts acute kidney injury, morbidity and mortality after pediatric cardiac surgery: a prospective uncontrolled cohort study. Crit Care 11: 127.

9. Soni SS, Cruz D, Bobek I, et al. (2010): NGAL: a biomarker of acute kidney injury and other systemic conditions. Int Urol Nephrol 42: 141-150.

10. Bennett M, Dent CL, Ma Q, et al. (2008): Urine NGAL predicts severity of acute kidney injury after cardiac surgery: a prospective study. Clin J Am Soc Nephrol 3: 665-673.

11. Faubel S, Lewis EC, Reznikov L, et al. (2007): Cisplatininduced acute renal failure is associated with an increase in the cytokines interleukin (IL)-1beta, IL-18, IL-6, and neutrophil infiltration in the kidney. J Pharmacol Exp Ther 322: 8-15.

12. Hanbeyoğlu A, Kazez A, Ustündağ B, Akpolat N (2011): Determination of urinary $\mathrm{N}$-acetyl- $\beta-\mathrm{D}$ glucosaminidase (NAG) levels in experimental blunt renal trauma. Ulus Travma Acil Cerrahi Derg 17: 475-481.

13. Ferguson MA, Vaidya VS, Bonventre JV (2008): Biomarkers of nephrotoxic acute kidney injury. Toxicology 245: 182-193.

14. Büget MI, Özkilitçi E, Küçükgergin C, et al. (2014): Early Diagnosis in Acute Kidney Failure: Neutrophil Gelatinase Associated Lipocain (NGAL), Kidney Injury Molecule-1 (KIM-1), Interleukine-18 (IL-18), Cystatin C. Türk Yoğun Bakım Derneği Dergisi 12: 94-100.

15. Liangos O, Wald R, O'Bell JW, et al. (2006): Epidemiology and outcomes of acute renal failure in hospitalized patients: a national survey. Clin J Am Soc Nephrol 1: 43-51.

16. Wasilewska A, Taranta-Janusz K, Dębek W, et al. (2011): KIM-1 and NGAL: new markers of obstructive nephropathy. Pediatr Nephrol 26: 579-586.

17. Ichimura T, Bonventre JV, Bailly V, et al. (1998): Kidney injury molecule-1 (KIM-1), a putative epithelial cell adhesion molecule containing a novel immunoglobulin domain, is up-regulated in renal cells after injury. J Biol Chem 273: 4135-4142.

18. Ling W, Zhaohui N, Ben H, et al. (2008): Urinary IL-18 and NGAL as early predictive biomarkers in contrast-induced nephropathy after coronary angiography. Nephron Clin Pract 108: 176-181.

19. Haase-Fielitz A, Bellomo R, Devarajan P, et al. (2009): Novel and conventional serum biomarkers predicting acute kidney injury in adult cardiac surgery - a prospective cohort study. Crit Care Med 37: 553-560.

20. Mishra J, Ma Q, Prada A, et al. (2003): Identification of neutrophil gelatinase-associated lipocalin as a novel early urinary biomarker for ischemic renal injury. J Am Soc Nephrol 14: 2534-2543.

21. Mishra J, Dent C, Tarabishi R, et al. (2005): Neutrophil gelatinase-associated lipocalin (NGAL) as a biomarker for acute renal injury after cardiac surgery. Lancet 365: 1231-1238.

22. Han WK, Bailly V, Abichandani R, et al. (2002): Kidney Injury Molecule-1 (KIM-1): a novel biomarker for human renal proximal tubule injury. Kidney Int 62: 237-244.

23. Lichosik M, Jun A, Jobs K, et al. (2015): Interleukin 18 and neutrophil-gelatinase associated lipocalin in assessment of the risk of contrast-induced nephropathy in children. Cent Eur J Immunol 40: 447-453.

24. Vaidya VS, Ramirez V, Ichimura T, et al. (2006): Urinary kidney injury molecule-1: a sensitive quantitative biomarker 
for early detection of kidney tubular injury. Am J Physiol Renal Physiol 290: 517-529.

25. Vaidya VS, Bonventre JV (2006): Mechanistic biomarkers for cytotoxic acute kidney injury. Expert Opin Drug Metab Toxicol 2: 697-713.

26. Parikh CR, Jani A, Melnikov VY, et al. (2004): Urinary interleukin-18 is a marker of human acute tubular necrosis. Am J Kidney Dis 43: 405-414.

27. Haase M, Bellomo R, Story D, et al. (2008): Urinary interleukin-18 does not predict acute kidney injury after adult cardiac surgery: a prospective observational cohort study. Crit Care 12: 96.

28. Royakkers AA, Korevaar JC, van Suijlen JD, et al. (2011): Serum and urine cystatin $\mathrm{C}$ are poor biomarkers for acute kidney injury and renal replacement therapy. Intensive Care Med 37: 493-501.

29. Nejat M, Pickering JW, Walker RJ, et al. (2010): Rapid detection of acute kidney injury by plasma cystatin $\mathrm{C}$ in the intensive care unit. Nephrol Dial Transplant 25: 3283-3289.

30. Casale AJ (2001): Urinary tract trauma. Pediatric Urology, Gearhart JP, Rink RC, Mouriquand PDE (eds.). W.B. Saunders Company, Philadelphia: 923-943.

31. Price RG (1992): Measurement of N acetyl $\beta$-D- glucosaminidase and its isoeenzymes in urine methods and clinical applications. Eur J Clin Biochem 30: 693-705.

32. Tataranni G, Farinelli R, Zavagli G, et al. (1987): Tubule recovery after obstructive nephropathy relief: the value of enzymuria and microproteinuria. J Urol 138: 24-27.

33. Neimark A, Fidirkin A, Celovalnikova I (1997): Enzymuria as early marker of nephritis. Int Urol Nephrol 29: 137-140.

34. Krishna KS, Kirubakaran MG, Pandey AP, et al. (1985): Urinary N-Acetyl- $\beta$-D-glucosaminidase and aminopeptidase $\mathrm{N}$ in the diagnosis of graft rejection after live donor renal transplantation. Clin Chim Acta 150: 69-85. 